\title{
MEDÉIA DE SÊNECA
}

\author{
MARIA DA GLORIA NOVAK* \\ Faculdade de Filosofia, Letras e Ciências Humanas \\ da Universidade de São Paulo
}

\begin{abstract}
RESUMO: O dramaturgo Sêneca interessa-se principalmente pela alma de suas personagens, com seus sentimentos, suas paixões, seus conflitos. Ouvindo-as falar, gritar, orar, pode-se bem prever o desenrolar da ação trágica. Em Medéia, os versos 919-53 apresentam-nos a heroina presa de sentimentos contraditórios: de um lado, a mãe, seu amor e seu coração; de outro, a esposa com sua cólera e seu espírito de maga.
\end{abstract}

PALAVRAS-CHAVE: amor; cólera; compaixão; vingança; tragédia.

Depois que, em 240 a.C., Lívio Andronico traduziu uma tragédia grega em latim, o gênero conheceu o progresso em Roma. Os grandes trágicos gregos, Ésquilo, Sófocles e Eurípides, foram imitados.

Dos primeiros teatrólogos romanos, Névio (séc. III), Quinto Ênio (239-169), Pacúvio (220-c.130), Ácio, o maior, talvez (c.170-c.86), restam fragmentos que nos permitem considerações a respeito de estilo e valor. Dos períodos de Cícero e Augusto, que não terão sido brilhantes do ponto de vista da tragédia, restam-nos alguns versos, referências, nomes, entre os quais o de Ovídio, que teria escrito uma tragédia, Medéia. Segue-se um hiato na produção de tragédias em Roma, até a idade adulta de Sêneca. Depois dele, o que houve certamente foi pouco e/ou não restou.

Todas as inquietações do pensador estão na obra do dramaturgo Lúcio Aneu Sêneca: a inconstância da sorte, os sacrifícios sangrentos, oráculos, presságios e profecias, crime e castigo, a natureza da alma e o post-mortem, a volta do homem ao seio dos Deuses, o destino e a fatalidade e, principalmente, as paixões humanas. E mais. Sêneca insiste, em toda a sua obra, em combater o medo à morte; por exemplo, em Naturales Quaestiones encontra-se este imperativo: contemne mortem, "despreza a morte" (II 59, 3).

Restam-nos do Cordovês nove tragédias de assunto grego, uma das quais, Hércules Eteu, tem tido sua autoria discutida, por Bayet, por exemplo, em 1934, 
embora Herrmann em 1925 já não a discuta. A pretexta Otávia, às vezes atribuída a Sêneca, alude a ocorrências talvez posteriores a sua morte.

As peças senequianas são diferentes das gregas. $\mathrm{Na}$ verdade, são adaptações ao gosto romano da época, plenas de declamação, descrições e lugares-comuns do estoicismo. Dupont $(1988,74)$ salienta que a presença desses lugares-comuns serve para marcar a norma humana a partir da qual se situam os heróis. De fato, a filosofia não é nem o centro nem o fim do teatro de Sêneca. O seu fim, como assinala Herrmann, é literário, e as peças não são nem dramas políticos de oposição nem críticas à religião (Herrmann, 1924, 237-46).

Destaque-se também que o Autor modifica e cria cenas. Por exemplo, em Medéia, a morte das crianças não é ouvida como em Eurípides (v. 1273.6-1294), é vista (970-1.1019); a cena de feitiçaria, narrada pela Ama (670-739), também não pertence à peça grega. Também são diferentes das gregas as peças do dramaturgo latino pelo que se costuma chamar ausência de climax: o protagonista surge logo no início da peça em toda a extensão de sua dor.

A ação, contundente, embora (em Medéia, como eu disse, a heroína mata os filhos diante do espectador), parece mais lenta, pois se delineia por meio das falas das personagens. Citemos, por exemplo, a primeira fala do rei em Édipo (1-81), o monólogo de Juno em Hércules furioso (1-124), ou a prece da heroína em Medéia (155). Em Fedra, logo após as palavras de Hipólito aos caçadores (1-84), a protagonista surge com o seu problema, conversando com a Ama, em um diálogo de sessenta e três versos (116-78). Ao meu ver, mais que o desenrolar dos acontecimentos, parecem interessar ao Autor os sentimentos das personagens, a luta intensa dos impulsos contraditórios e da razão.

Aliás, a pensarmos bem, as palavras comandam a ação. Através delas, o espectador vê a transformação do herói, e essa transformação é o cerne da tragédia senequiana (v. Dupont, 1988, 68). De fato, um dos grandes méritos do Cordovês está na criação das personagens e no estudo das paixões.

Os mitos, o dramaturgo usa-os com liberdade mas conservando as grandes linhas das lendas. Por outro lado, convém assinalar que ele respeita a regra das três unidades. Mas, segundo Herrmann (1924, 354-8), às vezes, talvez, forçando um pouco. Em Medéia, por exemplo, deve-se considerar a casa da heroína vizinha ao palácio. Há, também, alguns artifícios para forçar a unidade de tempo.

Medéia, peça em 1027 versos, tem como fontes principais Ovídio, Ênio, Apolônio de Rodes e, naturalmente, Eurípides. Mostra a feiticeira Medéia, neta do Sol, repudiada pelo marido e condenada ao exílio pelo rei, a tramar e depois executar a sua vingança. 
Antes de focalizar os episódios, gostaria de dizer algo sobre as circunstâncias, as personagens, o Coro e os Deuses.

Toda a situação da tragédia apresenta-se até o fim do $2^{\circ}$ episódio (116-300). Além disso, o Autor como que lança um facho de luz sobre o passado, iluminando a personalidade da feiticeira Medéia e os fatos que antecederam seu casamento com Jasão. Há, por outro lado, como que uma projeção para o futuro, na medida em que certos fatos passam a ser esperados, e possíveis, como conseqüência do presente, do passado e da personalidade da heroína. Ora é o rei Creonte quem ajuda a desvendar o passado (201.255 et seqs), ora a feiticeira narra e justifica seus crimes (131-6), conta sua origem e lamenta a felicidade perdida (207 et seqs). Queixa-se da inconstância da sorte (219-20). Mas não se arrepende dos antigos atos: ao contrário, deles se gloria (225 et seqs).

Assim é que as personagens são caracterizadas desde o início da peça: dão-se a conhecer e dão a conhecer umas as outras. Mesmo Jasão, o grande amor de Medéia, pai de seus filhos, que surge na cena 2 (431 et seqs) do $3^{\circ}$ episódio, é dado a julgar desde o prólogo e fica bem caracterizado no $2^{\circ}$ episódio. $\mathrm{O}$ espectador sabe quase imediatamente que ele é odiado (19-25), amado (140-1) e defendido (263-4). E sabe por quê. Humano e fraco (outrora dux ducum, "comandante dos comandantes", 233), tem a simpatia do rei e do Coro. Diz que sacrifica o primeiro casamento por amor aos filhos (437-9) e é a declaração desse amor (547-9) que determina a mais cruel vingança da esposa: a morte dos filhos.

O rei, Creonte, é visto sob três aspectos: através da opinião de Medéia ("orgulhoso pelo império pelasgo”, 178), através de sua opinião de si mesmo (252 et seqs) e através de sua atitude para com a heroína. Autoritário, embora (188-91 et pass.), permite-lhe que fale (202), assegura-lhe que as crianças ficarão bem após a sua partida (284) e cede à suplicante, concedendo-lhe um dia mais de permanência no reino (295).

A Ama, que tenta fracamente e sem sucesso moderar os impulsos da feiticeira, ora concorda com a vingança (153), ora aconselha a fuga (170); a seguir, age como auxiliar na preparação do crime (568-78.843-4) e, mais tarde, volta a aconselhar a fuga (891-2). Duplo ou sombra da heroína (?), parte com ela, no carro da salvação.

Medéia é uma das maiores criações de Sêneca. Inumana, posto que feiticeira, poderia atingir a humanidade pela razão e pela uirtus. Mas, ao longo de toda a peça, quer ser desumana, quer ser criminosa. Veremos, ao focalizar os episódios, a sua luta para permanecer fiel ao seu passado de crimes (cf., por 
exemplo, 41 et seqs). Luta com sua consciência, e os lampejos de humanidade vão sendo vencidos.

O Coro não se mistura à ação, exceto no $5^{\circ}$ episódio, quando o Mensageiro lhe relata o incêndio do palácio (879-90). Ainda assim, não interfere.

São quatro os cantos corais.

O primeiro (56-115), que revela influência de Catulo, é um canto nupcial para Jasão e a filha do rei.

O segundo (301-79) contrapõe a vida pacífica dos antepassados à conquista dos mares e refere a nau Argo: sua audácia e os perigos que enfrentou.

O terceiro (579-669) focaliza o ódio ("cego é o fogo estimulado pela ira”, 591) e pede aos Deuses que poupem Jasão, que submeteu o mar (595-6). Poupem-no apesar da fúria do senhor dos mares porque foi vencido o seu reino (597-8); e refere os castigos dos Argonautas. Fatalidade? Crime e castigo? Apenas fidelidade à lenda?

O quarto (849-78), propositadamente curto, antecede a catástrofe e focaliza a heroína e seu ódio. E invoca Febo: que o dia seja curto e Corinto, sem demora, se livre do perigo.

Sobre os Deuses em Medéia não há muito a dizer. Sêneca, de maneira geral, respeita a justiça divina e não insiste na sua vingança, o que torna delicada a análise do terceiro canto coral, com a alusão à fúria de Netuno pela invasão dos mares: dois versos logo após uma prece aos Deuses para que poupem Jasão. Trata-se, ao meu ver, de recurso poético. E recurso teatral e poético seriam também as próprias preces: Herrmann lembra Naturales Quaestiones (II 35, 1), em que o Autor cita opinião estóica de que as preces são apenas o alívio de um coração doente. Medéia invoca os Deuses, principalmente Hécate, o que parece confirmar as impressões.

\section{Episódios}

Considero, como Herrmann, cinco episódios, entendendo o primeiro como prólogo e a última cena do quinto como epílogo. Vejamos: prólogo (1-55); $2^{\circ}$ episódio (116-300); $3^{\circ}$ episódio (380-578); $4^{\circ}$ episódio (670-848); $5^{\circ}$ episódio (879-1027); epílogo (978-1027).

O primeiro episódio, ou prólogo (1-55), é uma prece às divindades superiores e inferiores e caracteriza a protagonista. Medéia, num crescendo, passa da invocação aos Deuses ao desejo de agir (26-7), ao desejo de vingar-se porque o marido a abandona para desposar a filha do rei. Lembra os antigos crimes: parecem-lhe pe- 
quenos: quer algo maior (49-50). Quer a adesão do universo à sua dor (31), quer, para si, o poder do Sol (32).

O segundo episódio (116-300) apresenta-a primeiro com a Ama, depois com Creonte. Este segundo episódio prepara a catástrofe, na medida em que o rei concede à suplicante mais um dia para preparar o exílio (295), tempo mais que suficiente para a realização da vingança. (No diálogo entre a heroína e o rei, alguns lugarescomuns sobre o poder; ex. gr., iniqua numquam regna perpetuo manent, 196.)

No terceiro episódio (380-578), primeiro a Ama descreve a ira da feiticeira e enche-se de temor: "transborda o furor", diz (392). Depois a própria Medéia promete-se atos terriveis, embora, com Jasão, tente ainda mostrar-se fraca e solucionar a crise, pedindo-lhe que fuja com ela (524). O marido não cede à sua súplica: a vingança delineia-se no espírito da infeliz, que se domina e se faz humilde (549-57). Na terceira e última cena desse episódio (560-78), incentiva-se ela ao crime e pede auxílio à Ama para a execução da primeira parte deste.

O quarto episódio (670-848), ao contrário do que se poderia esperar, não é o da catástrofe. Compreende o monólogo da Ama, que descreve a feiticeira entregue à feitiçaria, e apresenta a própria feiticeira a agir, a rememorar antigas façanhas e a implorar Hécate para o sucesso da vingança (811 et seqs).

O quinto episódio (879-1027), em três cenas, põe o espectador diante da catástrofe e do epílogo.

Na primeira cena (879-90), o Mensageiro conta ao Coro que o palácio do rei está em chamas, o rei e a filha, mortos; e que o crime é sobrenatural, pois a água aviva o fogo.

Na segunda cena (891-977), a maga incentiva-se a atingir mais de perto Jasão (897-900). Relembra os antigos crimes, segundo ela mesma crimes de criança: agora ela é Medéia (909-10). Define-se a sua dualidade: primeiro, ela não sabe "o que decidiu, feroz, o espírito". Imediatamente a seguir, ela sabe: deve sacrificar os filhos (924-5). Horroriza-se, porém, ante a idéia. Mas depois sacrifica o primeiro (970-1). Ouve a chegada de Jasão e dos soldados e, sem abandonar a Ama, refugia-se no ponto mais alto da casa, de onde sabe que será salva: é cada vez mais Medéia, feiticeira, neta do Sol (975).

No epílogo (978-1027), logo no início ainda não se apagou totalmente a dualidade da heroína. Voltam lampejos de humanidade (982-90): exulta com o primeiro crime, porém hesita em prosseguir. A inumanidade encontra resistência, para vencer enfim. O epílogo é brutal: como eu disse, ao contrário do que ocorre por via de regra na tragédia grega. Medéia totalmente feiticeira como no passado, 
totalmente inumana porque dominada pela ira, e totalmente responsável porque quis ser dominada pela ira, foge pelos ares num carro conduzido por duas serpentes.

A peça termina com as palavras de Jasão: uade [...] testare nullos esse, qua ueheris, Deos, "vai e sê testemunha de que não há Deuses por onde passas"; ora, se é verdade que o homem se une a Deus pela uirtus, como pretende Sêneca, não pode mesmo haver Deuses no caminho de Medéia.

O texto que escolhi como ilustração da peça e da arte do Cordovês pertence à segunda cena do quinto episódio. Creúsa e o pai estão mortos. Medéia está diante do mais hediondo crime: o infanticídio. Apresento-o primeiro no original e depois em tradução minha.

\section{[...] Stulta properaui nimis:}

ex paelice utinam liberos hostis meus

aliquos haberet! Quicquid ex illo tuum est

Creusa peperit. Placuit hoc poenae genus

meritoque placuit: ultimum, agnosco, scelus

animo parandum est: liberi quondam mei, uos pro paternis sceleribus poenas date.

Cor pepulit horror, membra torpescunt gelu pectusque tremuit. Ira discessit loco materque, tota coniuge expulsa, redit. Egone ut meorum liberum ac prolis meae fundam cruorem? Melius, a demens furor, incognitum istud facinus ac dirum nefas a me quoque absit; quod scelus miseri luent? Scelus est Iason genitor et maius scelus Medea mater: occidant, non sunt mei; pereant, mei sunt. Crimine et culpa carent, sunt innocentes: fateor. Et frater fuit. Quid, anime, titubas? Ora quid lacrimae rigant uariamque nunc huc ira, nunc illuc amor diducit? Anceps aestus incertam rapit; ut saeua rapidi bella cum uenti gerunt utrimque fluctus maria discordes agunt 
dubiumque feruet pelagus, haut aliter meum

cor fluctuatur. Ira pietatem fugat

iramque pietas. Cede pietati, dolor.

Huc, cara proles, unicum afflictae domus

solamen, huc uos ferte et infusos mihi

coniungite artus. Habeat incolumes pater,

dum et mater habeat: urguet exilium ac fuga.

Iamiam meo rapientur auulsi e sinu

flentes, gementes, exulis: pereant patri:

periere matri. Rursus increscit dolor

et feruet odium: repetit inuitam manum

antiqua Erinys. Ira, qua ducis sequor

Estulta, apressei-me demais:

oxalá da concubina meu inimigo tivesse

alguns filhos! Tudo o que dele veio e é teu

Creúsa conquistou. Está decidido este modo de vingança,

e decidido com razão: um último crime, reconheço,

deve ser preparado pelo espírito: filhos outrora meus,

vós, pelos crimes paternos, sede punidos.

O horror feriu o coração, o corpo entorpece de frio,

e o peito estremeceu. Afastou-se a ira

e, expulsa totalmente a esposa, volta a mãe.

Eu mesma derramaria o sangue de meus próprios filhos

e de minha descendência? Melhor, ah!, fúria insana,

se afaste também de mim esta façanha inaudita,

esta monstruosidade sinistra; que crime pagarão os infelizes?

O crime é Jasão, o pai, e maior crime

é Medéia, a mãe: morram, não são meus;

percam-se, são meus. Estão livres de pecado e culpa,

são inocentes: confesso. Também o foi meu irmão.

Por que, espírito, vacilas? As faces, por que as orvalham

lágrimas, e a indecisa, ora para aqui a ira, ora para lá o amor a conduz?

Duplo turbilhão arrasta a que não tem certeza; 
assim como, ao lutarem furiosamente rápidos ventos,

de ambos os lados as ondas, discordes, levantam os mares

e, perigoso, ferve o pélago, assim mesmo se

agita meu coração. A ira põe em fuga a piedade,

a piedade, a ira. Cede à piedade, dor.

Para cá, minha descendência querida, consolo único de um lar 945

despedaçado, vinde para cá e aproximai-vos de mim

e abraçai-me. Tenha-os incólumes o pai,

desde que os tenha também a mãe. Estão iminentes exílio e fuga.

Já, já, arrancados de meu próprio seio de exilada,

serão arrastados, chorando, gemendo: percam-se para o pai: 950

perdidos estão para a mãe. De novo cresce a dor,

e ferve o ódio: torna a procurar a mão constrangida

a antiga Erínis. Ira, por onde me levas sigo-te.

Os períodos são curtos, as orações, curtíssimas. Poucas coordenadas, em geral assindéticas, pouquíssima subordinação. Nos trinta e cinco versos, apenas oito formas no subjuntivo. $O$ estilo é incisivo, lapidar, aflito: resulta de profunda emoção.

V. 919: Stulta, properaui nimis, "estulta, apressei-me demais". O sujeito é a esposa com sua vingança. $O$ verbo está no perfeito, no modo da realidade: é um fato que a vingança se apressou. A seqüência mostra o sentido desse properaui: "matei Creúsa antes que ela desse a Jasão filhos que eu pudesse matar".

V. 920-1: ex paelice utinam liberos hostis meus aliquos haberet, "da concubina oxalá meu inimigo tivesse alguns filhos". Haberet, no imperfeito do subjuntivo com utinam, indica irrealidade no presente: "oxalá tivesse, mas não tem”.

No verso 920, hostis meus, “meu inimigo”, é Jasão, agora estranho, outrora o amor pelo qual Medéia roubara e matara.

Ainda no verso 921: quicquid ex illo tuum est, "tudo o que veio dele e é teu": verbo no presente, no modo da realidade: é teu. Quicquid, "tudo": o marido, os filhos, o status, a casa, tudo. Illo, refere Jasão: sem qualquer conotação enaltecedora, mas sim de distância: tão longe dela, agora.

Ainda no verso 921, tuum, "teu": Medéia fala consigo mesma; não diz, porém, meum, mas tuum: este possessivo é o primeiro indício da dualidade da protagonista neste passo. 
V. 922: Creusa peperit, "Creúsa conquistou". O verbo está no perfeito, no modo da realidade. Enfatizo a oposição presente, é teu, perfeito, conquistou: Medéia não abre mão da posse.

Ainda no verso 922: placuit hoc poenae genus, "está decidido este modo de vingança”. Vejo neste perfeito, placuit, sentido de presente: agradou, está decidido. Poena, que aqui é mesmo a vingança, tem o sentido de castigo que se impõe por um delito. A heroína se vê com direito a uma reparação exemplar. $\mathrm{O}$ advérbio merito, “com razão", no verso seguinte, o confirma. Também o confirma o verso 925: uos pro paternis sceleribus poenas date, "vós, pelos crimes paternos, sede punidos".

V. 923: meritoque placuit, "e decidido com razão": mesmo verbo do verso anterior, mesmo sujeito: "este modo de vingança".

V. 923-4: ultimum, agnosco, scelus animo parandum est, "um último crime, reconheço, deve ser preparado pelo espírito". Este ultimum scelus, no verso 923, tem uma carga semântica muito grande: não é só o último senão também o maior: o que atinge o grau supremo: é o maior contra a natureza: e deve ser cometido pelo espírito. Medéia não está sozinha: ela tem o seu espírito. Mas se destaca dele. E este é o segundo indício de sua dualidade neste passo.

Ainda no verso 923, agnosco, "reconheço", é a segunda forma verbal na primeira pessoa do singular; entretanto o sujeito de agnosco, a mãe, não é o mesmo de properaui (919), a esposa. Agnosco, "reconheço", que ecoa no possessivo do verso 924, mei, "meus", opõe-se a animo, "pelo espírito", e ao dativo de interesse, oculto mas subentendido, de placuit, que também é o espírito, evidentemente: agradou ao espírito.

V. 924-5: liberi quondam mei [...] poenas date, "filhos outrora meus, vós, pelos crimes paternos, sede punidos". Verbo no imperativo: date (925). Inciso no vocativo liberi quondam mei, o advérbio quondam, "outrora", dá maior dimensão à luta que se trava na heroína. Não só de um lado está a mãe (em quem se destaca o aspecto natureza) e de outro lado está a esposa (com seu aspecto de maga): também a mãe está bipartida: ora reconhece como seus os filhos, ora os repugna como filhos do inimigo: dualidade que volta, brutal, nos versos 934-5: occidant non sunt mei; pereant, mei sunt, "morram, não são meus; percam-se, são meus"; a feiticeira julga-se, pois, com direito sobre eles... até para matá-los.

O espírito desumano de Medéia tomou a sua decisão. E ela, a mãe, sabe: agnosco (923), "reconheço". Mas ao invocar ela os filhos, revolta-se a sua humanidade. A protagonista, sob intensa emoção, descreve-se. O quadro é nítido: nos versos 926-7, o quadro físico; a seguir, nos versos 927-8, o moral. 
V. 926: cor pepulit horror, "o horror feriu o coração". O objeto inicia o verso e o objeto é cor, "coração", e se opões a animus, "espírito, mente", como também se opõem a animus corpo e peito (membra e pectus), sujeitos das orações seguintes.

No verso 926, o verbo está no perfeito, pepulit, "feriu”: o coração foi e está ferido de horror. No mesmo verso (926) membra torpescunt gelu "o corpo entorpece de frio". Torpescunt: presente, intransitivo, incoativo: começa o corpo a entorpecer, a enregelar-se: é todo um processo em desenvolvimento.

V. 927: pectusque tremuit, "e o peito estremeceu", com tremuit no perfeito. É importante observar a forma torpescunt do verso anterior, presente e incoativo, entre dois perfeitos: vê-se bem a imagem: o coração foi golpeado; estremeceu o peito; e o frio começa a enregelar os membros.

Ainda no verso 927: Ira discessit loco, "afastou-se a ira”. Verbo no perfeito, no modo da realidade: afastou-se a ira e, por enquanto, se mantém afastada: a confirmação está na oração seguinte: materque redit, "volta a mãe". Verbo no presente: redit: volta a mãe, depois que se afastou a ira, e volta com toda a sua força: no mesmo verso, incisa, a expressão tota coniuge expulsa, "expulsa totalmente a esposa": afastam-se ao mesmo tempo a esposa e a ira. O sujeito do ablativo absoluto, "a esposa toda”, com sua mágoa e seu desejo de vingança, dá lugar à mãe.

V. 929-30: Egone ut meorum liberum ac prolis meae fundam cruorem?, "eu mesma derramaria o sangue de meus próprios filhos e de minha descendência?" É importante observar: 1) que o sujeito, ego, "eu”, em destaque no início do verso, é o mesmo de agnosco, "reconheço": Medéia mãe; 2) o emprego dos dois possessivos de primeira pessoa, meorum / meae, "de meus / de minha": a mãe sente, aqui, os filhos como seus. Não outrora, como no verso 924, mas agora, no momento da fala.

V. 930-2: Melius, a demens furor [...] absit, "Melhor, ah!, fúria insana, se afaste também de mim este crime inaudito, esta monstruosidade sinistra". Antes se afaste: absit, subjuntivo de desejo: desejo realizável no presente: e isto é muito importante: embora ao fim não se realize, o desejo, a certa altura, é realizável.

Ainda no verso 930: a demens furor: Medéia, aqui, é a mãe: tem consciência da irracionalidade de sua fúria.

V. 931: incognitum istud facinus ac dirum nefas, "essa façanha inaudita, essa monstruosidade sinistra”: este crime que é supremo (ultimum, no verso 923) é também primeiro (incognitum, no verso 931), e não é só um crime de impiedade (nefas, 931) mas a monstruosidade total e sinistra do crime contra a natureza.

V. 932: quod scelus miseri luent?, "que crime pagarão os infelizes?" Miser quer dizer "lamentável, digno de piedade". A mãe refere-se aos filhos com tristeza e piedade: humanamente sente-os como seus e humanamente se entristece. 
V. 933-4: Scelus est Iason genitor et maius scelus Medea mater, "o crime é Jasão, o pai, e maior crime é Medéia, a mãe". Medéia perguntou-se: agora responde. Verbo no modo da realidade: scelus est, "o crime é". Duplo crime, dupla desgraça: o crime, o maior crime. O termo scelus, no verso 932, tem o sentido de "crime"; em 933, o de "infelicidade": porque ter Jasão por pai e Medéia por mãe não é um crime: é uma desgraça.

V. 934: occidant, non sunt mei, "morram, não são meus": occidant, subjuntivo de desejo, com possibilidade no presente.

V. 935: pereant, mei sunt, "percam-se, são meus". Construção absolutamente paralela à anterior. Aqui, no verso 935, esperar-se-ia uma oposição total: não se percam: são meus. Mas não: a heroína sente os filhos como seus e não seus. Em ambos os casos, devem morrer. O verso 951 explica melhor a razão disto: periere matri, "estão já perdidos para a mãe".

V. 935-6: crimine et culpa carent, sunt innocentes, fateor, "estão livres de pecado e culpa, são inocentes: confesso”. O sujeito de fateor é a maga. Em todo este momento quem está em evidência é a maga. É o espírito vingativo de Medéia. Mesmo na expressão Medea mater, no verso 934, está implícita a feiticeira: por isso a desgraça das crianças.

Ainda no verso 936: et frater fuit, "também o foi meu irmão". Três únicas palavras: et frater fuit. Surge um dado novo: não é só a esposa que deseja vingança, é também a irmã, que, abandonada, lança agora sobre Jasão a culpa de seus próprios crimes.

V. 937: quid, anime, titubas?, "por que, espírito, vacilas?" Anime é um vocativo; note-se a ausência de possessivo, a sugerir, ainda uma vez, a dualidade de Medéia. Titubas é um presente real: o espírito está vacilando. Estará a mãe vencendo o espírito?

Ainda no verso 937: ora quid lacrimae rigant?, "as faces, por que as orvalham lágrimas?" Rigant é também um presente, também real como titubas. A infeliz analisa-se. Até o verso 944, em que surge o primeiro de três imperativos seguidos, os verbos estão todos no presente no modo da realidade: titubas, "vacilas", rigant, "orvalham" (937), diducit, "conduz", rapit, "arrasta” (939), bella gerunt, "lutam” (940), agunt, "levantam” (941), feruet, "ferve" (942), fluctuatur, "agita-se”, fugat, "põe em fuga” (943).

V. 937-9: quid [...] uariamque nunc huc ira, nunc illuc amor diducit?, "e a indecisa [que é a própria Medéia] por que ora para aqui a ira, ora para lá o amor a conduz?" O verbo diducit significa "levar para lados diferentes": o sentido é enfatizado 
pelos advérbios huc / illuc, "para cá / para lá". Ira e amor são os sujeitos antagônicos de diducit.

V. 939: anceps aestus incertam rapit, "duplo turbilhão arrasta a que não tem certeza". E quem não tem certeza é Medéia: incertam e, no verso 938, uariam, "indecisa": está a infeliz dividida entre a ira e o amor.

Ainda no verso 939: anceps aestus. Aestus é o ardor, é o turbilhão: pode ser a agitação do mar, pode ser a maré; a imagem, aqui, é de mar, como se vê pelos termos fluctus, "ondas", maria, "mares" (941), pelagus, "pélago" (942), fluctuatur, "agita-se" (943). E anceps pode ser duplo, incerto; pode ser duvidoso, perigoso.

V. 940-3:

ut saeua rapidi bella cum uenti gerunt

utrimque fluctus maria discordes agunt

dubiumque feruet pelagus [...]

e assim como (ao lutarem furiosamente rápidos ventos) de ambos os lados as ondas, discordes, levantam os mares e, perigoso, ferve o pélago $[\ldots]:$

isso é o primeiro termo de uma comparação. Dubius vem de duo, e pode significar "dúbio, duvidoso", naturalmente, e também "hesitante, incerto", ou "perigoso".

V. 942-3: haut aliter meum / cor fluctuatur, "assim mesmo se agita meu coração": este é o segundo termo da comparação. Meum cor, sujeito de fluctuatur. E me parece importante observar a anteposição do possessivo: ênfase para a posse e para cor: meum em fim, cor em início de verso. Além disso, ao meu ver, cor (943) opõe-se a anime (937): outra vez a dualidade da heroína: de um lado o espírito da maga, de outro, seu coração humano; de um lado, ira, de outro, amor (938). Neste momento, é principalmente mãe e diz meum cor. Observe-se que não dissera mi anime, e simplesmente anime (937).

Fluctuatur diz-se do mar quando está agitado. A comparação do turbilhão que se processa em Medéia com o turbilhão do mar é soberana: a força, o mistério escondido nas profundezas, a beleza, o horror, tudo está aí. Acresce que o mar é parte substancial do cenário de sua história.

Ainda no verso 943: ira pietatem fugat, "a ira põe em fuga a piedade". Notese que fugat é um presente no modo da realidade.

V. 944: iramque pietas, "a piedade [põe em fuga] a ira": coordenada aditiva à anterior, opõe-se intimamente a ela: mesmos termos, funções invertidas. Período 
simplíssimo e lapidar, resume intensa luta: esta que vimos acompanhando desde o início da leitura: ira e pietas, "ira e piedade", animus e cor, "espírito e coração", Medea coniunx e Medea mater, "Medéia esposa" e "Medéia mãe".

No mesmo verso 944: cede pietati, dolor, "cede à piedade, dor": breve, imperativo (ou suplicante?), este período põe face a face a piedade e o motivo da ira: a dor. Não, aqui, a dor da mãe, senão a dor da esposa, a dor que se opõe à piedade. Mas é a mãe quem ordena (ou pede?). Em todo este momento, as palavras são de Medéia mãe.

Nos versos 945-7, esta invoca pela segunda vez os filhos [a primeira foi nos versos 924-5]:

Huc, cara proles, unicum afflictae domus

solamen, huc uos ferte et infusos mihi

coniungite artus (945-7)

para cá, minha descendência querida, consolo único de um lar despedaçado, vinde para cá e abraçai-me.

Note-se a expressão unicum afflictae domus solamen: Medéia identifica-se ao lar: afflictae domus.

V. 947: habeat incolumes pater, "tenha-os incólumes o pai". Habeat, subjuntivo potencial, ligado a uma condição, que está no verso 948: dum et mater habeat, "contanto que os tenha também a mãe".

No mesmo verso 948, a oração urguet exilium ac fuga, "estão iminentes exílio e fuga”, parece-me ligar-se mais ao que segue do que ao que precede. Consiste, ao meu ver, no início de uma reviravolta. Medéia, que se enterneceu e quer ceder à piedade (944) e chama para junto de si os filhos (945-7) e os quer incólumes (947), repentinamente volta à realidade (estão iminentes exílio e fuga, 948), e cede à ira. Vrguet (948) está no presente no modo da realidade e está no singular com sujeito composto, o que é comum em latim mas me parece, aqui, ter grande significação: unem-se no pensamento da heroína exílio e fuga.

V. 949-50:

iamiam meo rapientur auulsi e sinu

flentes, gementes, exulis, 
agora mesmo, arrancados de meu próprio seio de exilada, serão arrastados, chorando, gemendo:

com o verbo no futuro, rapientur.

No mesmo verso 950: pereant patri, “percam-se para o pai”. Pereant é um subjuntivo de desejo: mais que um desejo realizável no presente, vejo aqui a ameaça de um futuro imediato e negro, que anteceda o futuro rapientur, "serão arrastados" (949).

V. 951: periere matri, "estão perdidos para a mãe". Verbo no perfeito, no modo da realidade: fato consumado: os filhos estão, já, perdidos para Medéia, o que explica a ameaça do verso anterior, pereant patri.

V. 951-2: rursus increscit dolor et feruet odium, "de novo cresce a dor e ferve o ódio". Rursus, "de novo", comanda ambas as orações: tanto de novo cresce, como ferve de novo; e as duas orações são paralelas: ao mesmo passo cresce a dor e ferve o ódio.

Aí está a segunda ocorrência de dolor; a primeira, no verso 944, é um vocativo, numa súplica de que se afaste. Aqui (951) é o sujeito de increscit, "cresce": a dor não se afastou: ao contrário, cresce e ameaça. É também a segunda ocorrência de feruet, “ferve". Na primeira, no verso 942, aplica-se a pelagus; aqui (952), a odium, e há certa identificação dos dois termos...

Medéia descreve-se e conserva, na descrição, o mesmo distanciamento dos versos 926-8, como se descrevesse outro alguém. Lá cor, membra e pectus, ira e mater; aqui, dolor, odium. Nenhum pronome, nenhum possessivo, nenhuma indicação de que tudo isto é ela mesma: lá, humana, mãe; aqui, inumana, esposa.

V. 952-3: repetit inuitam manum antiqua Erinys, "torna a procurar a mão constrangida a antiga Erínis". Nestes versos 952-3, um contraste resume o quadro: a mão constrangida, a mão materna, que não deseja ferir, é o objeto de repetit; a antiga Erínis é o sujeito de repetit: é a vingança da esposa forçando. No centro, Medéia, que, nos últimos trinta e quatro versos e meio, lutou consigo mesma, ou viu lutarem no seu âmago amor e ódio, piedade e ira e, o que é pior, humanidade e inumanidade. E a humanidade cede. Vence a antiga Erínis: dois pontos: ira, qua ducis sequor, "ira, por onde me levas sigo-te". É a quinta ocorrência do termo ira. Em três ocorrências, é sujeito; das três ocorrências em que é sujeito, uma vez se afasta (927) e duas vezes age (938.943); em uma ocorrência é o objeto de fugat, portanto, afasta-se também (944); aqui, na quinta ocorrência, é vocativo: mas há, neste verso (953), uma sexta ocorrência, subentendida: tu, ira: sujeito de ducis: a ira, enfim, comanda. 
O sujeito de sequor, "sigo", é Medéia mãe, Medéia humana, Medéia coração, vencida. À ira identifica-se o espírito, identifica-se a antiga Erínis, identifica-se Medéia inumana, Medéia esposa, Medéia maga.

A sorte dos meninos está lançada: a mãe, arrastada pela esposa, cometerá o crime contra a natureza, e permanecerá maga e fugirá no carro do Sol.

Em suma, podemos ver neste texto cinco momentos diferentes.

Primeiro (919-25): decisão da vingança maior: ultimum scelus animo parandum est, "um último crime deve ser preparado pelo espírito" (923-4).

Segundo (926-32): enternecimento da heroína: ira discessit loco / materque redit, "afastou-se a ira e volta a mãe" (927-8).

Terceiro (933-6): desejo de Medéia de justificar o novo crime com o antigo: occidant [...] sunt innocentes, fateor. Et frater fuit, "morram [...] são inocentes, confesso. Também o foi meu irmão" (934.936).

Quarto (937-48): indecisão: ira pietatem fugat / iramque pietas, "a ira põe em fuga a piedade, a piedade, a ira" (943-4).

Quinto e último (948-53): a lógica inumana: [...] pereant patri; periere matri, "percam-se para o pai; estão perdidos para a mãe" (950-1); e a decisão final: ira, qua ducis sequor, "ira, por onde me levas sigo-te" (953).

Todo este passo é de luta entre Medéia inumana, como diria Dupont, desumanizada pela ira a ponto de poder cometer um crime contra a natureza, e Medéia humana e mãe, entre Medéia tomada pela ira e sua consciência, entre Medéia e sua razão.

Podemos entendê-lo não apenas pela imagem do fluxo e refluxo da maré e sim, muito mais, como a violenta luta dos furiosos ventos contrários, que levantam os mares e podem causar destruição e morte.

\section{NotA}

* Professora Doutora de Língua e Literatura Latina do Programa de PósGraduação em Letras Clássicas da FFLCH-USP.

\section{REFERÊNCIAS BIBLIOGRÁFICAS}

BAYET, J. Littérature latine. Paris: A. Colin, 1965. 
DUPONT, F. Le théâtre latin. Paris: A. Colin, 1988.

HERRMANN, L. Le théâtre de Séneque. Paris: "Les Belles Lettres", 1924.

SENECA'S. Tragedies. Cambridge, Mass.: W. Heinemann, 1960. t. I.

SÉNĖQUE. Tragédies. Paris: "Les Belles Lettres", 1964. t. I.

NOVAK, Maria da Gloria. Médée de Sénèque.

RÉSUMÉ: Le dramaturge Sénèque s'intéresse surtout à l'âme de ses personnages, leurs sentiments, leurs passions, leurs conflits. À les entendre parler, crier, prier, on peut bien prévoir le déroulement de l'action tragique. Dans Médée, les vers 919-53 nous présentent l'héroïne en proie à des sentiments contradictoires: d'un côté, la mère, son amour et son coeur; de l'autre, l'épouse, sa colère et son esprit de magicienne.

MOTS-CLÉS: amour; colère; compassion; vengeance; tragédie. 